\title{
Study on Variables Influencing the Employee Empowerment Case Study: Industries of Markazi Province
}

\author{
Gholamreza Fatahi-Bayat \\ Lecturer University of Applied Sciences Central Province and deputy of Taklan Company, Email: rfbayat@yahoo.com
}

Ahmad Goudarzi

Expert in Development-Economy of Jihad Daneshgahi, Markazi Province, 09183611080,Email: Ah.Goodarzıgmail.com

Mohammadreza Goudarzi

Head of Arak oil and pipeline transportation office, Email: sajad_goodarzim@yahoo.com

\section{Doi:10.5901/mjss.2016.v7n5s1p102}

\section{Abstract}

This study seeks to investigate the variables affecting the employee empowerment in manufacturing companies of Markazi province. The data is collected from forty private, non-private, and governmental manufacturing companies with more than fifty employees in different posts in Arak, Khomeyn, Mahallat, Shazand, Tafresh, Ashtian, and Saveh cities of Markazi Province and the correlation of variables is measured by SPSS software and Pearson coefficient Table. The results of this research indicate that the personal, structural, managerial and environmental factors relatively have maximum correlation with employee empowerment in manufacturing companies of Markazi Province.

Keywords: Empowerment, human resources, internal factors, environmental factors, manufacturing companies

\section{Introduction}

The human resource is now known as the first cause of community development. There are numerous countries where are in poverty and underdevelopment with regard to the wealth and natural and groundwater resources. In contrast, there are some countries where are in the best development situation with poor resources. In fact, the human resource management achieves the personal, group and organizational objectives by process of investigation and creation of suitable attraction, training, employment, maintenance, health and development of human resources conditions. The employee empowerment is a key task of human resource management.

\section{Problem Statement}

The empowerment is a new concept which has attracted most of the management and organizational psychology researchers, experts and authorities since the late 1980s. The empowerment is one of the most promising concepts in the business world and it had not been taken into consideration, but it has become a matter of days. Despite much debate about the benefits of empowerment, it has been less utilized (Blanchard et al, translated by Amini, 2000, p. 11). Despite the fact that the empowerment enables the managers to use all individuals' knowledge, skills and experience in the organization, unfortunately there are still a few numbers and groups which know the way of creating an empowerment culture. Queen \& Spreitizer (1997) believe that despite creating the competitive advantage for an organization by empowerment and despite the fact numerous managers agree that the empowerment is desirable, most of the organizations have difficulty in implementing it. Whetten \& Cameron (1998) believe that the managers multiply their efficiency by empowerment, and thus their organizations and they become will become more efficient and be able to be different. Despite the fact that most of the managers consider the empowerment as the skills which should be implemented and analyzed, its actual implementation is rarely done in management. Queen \& Spreitizer (1997), Tomas \& VItavs (1990), and Ford \& Futler (1995) have argued that the empowerment is a complex and multidimensional concept with different meanings for different people. 
Queen \& Spreitizer (1997) have identified two different approaches for empowerment according to the literature review and field study of middle managers in leading companies. The first approach is mechanical or communicational. This empowerment approach defines the empowerment synonymous with delegation of authority and decision-making power for lower levels of organization. The second approach is organic (incentive) or cognitive. This approach sees the empowerment as a multidimensional concept according to employees' perceptions and opinions about themselves in job and organization and as the process of increasing the employees' internal attitude in doing the limited tasks. (Abdollahi, Naveh Ebrahim, 2006)

In any case, the empowerment is a continuous process based on which the labor should have a kind of selfconfidence, self-appraisal and be aware of his abilities and capabilities to achieve the goals, and thus achieve the targets by increasing his ability (Farrokhi, 1997, p. 76). In fact, the empowerment means releasing the individual internal force for amazing achievements. This strategy means giving the power; in other words, we help people to improve their sense of self-esteem, overcome their inability or helplessness, and mobilize the passion in doing the activities and their intrinsic motivation to perform their tasks (Blanchard, 2000, p. 39).

Three elements which create the empowerment in the workplace include the attitudes, relationships and organizational structure each which should be changed for making the employees empowered, otherwise the efforts will go to waste. An empowered workplace is an environment where the employees are the main driving forces. The empowerment provides the potential for utilization of human ability source which is not fully used. The empowerment will not be achievable through forces by managers with instructions, but it is a process which requires acceptance of empowerment culture and employees' participation (Arstd, 1997, p. 135). In other words, the empowerment of human resources means establishing the necessary capacity in staff for enabling them to create value added in the workplace as well as playing their roles and responsibilities with efficiency in the organization.

The empowerment has general and specific meanings and numerous definitions, and this diversity of definitions and approaches has made problems for integration of this concept, so that the factors are used such as the internal motivation, perception and commitment, job structure, power or authority delegation, and sharing the resources and information. (Robbins et al. 2002, p. 145)

The written texts show three types of human resources empowerment conceptualization as follows:

- Empowerment is the synonymous with delegation of authority and decision-making power to subordinates.

- Empowerment is a motivational factor which is increased through individual self-efficacy.

- The employee empowerment is a psychological concept which is associated with the individual states, emotions, and beliefs about job and organization and is defined as the process of enhancing the intrinsic motivation and has 5 dimensions including the sense of competency (self-efficacy), self-determination (choice right), efficiency (impact), meaningfulness (valuable) and sense of confidence (security). Development of five mentioned dimensions has numerous results and benefits. According to studies, if the people feel empowered, it will have both personal and organizational benefits. On the other hand, the negative outcomes are obtained when people experience opposite aspects of empowerment such as the disability, distress and self-alienation.

\section{Necessity and Importance of Human Resources Empowerment}

Conger \& Kanagu (1988) have mentioned the following reasons for severity of attention to empowerment:

- The studies of management skills indicate that empowering the subordinates is an important part of organizational and managerial effectiveness.

- The analysis of power and control in organizations suggests that involving the employees in power and control increases the organizational effectiveness.

- The experience of making group in the organization indicates that the employee empowerment strategies play important roles in development and survival of group.

Given the above-mentioned cases, this study is seeking to investigate the status of human resources empowerment in industries of Markazi Province as well as its effective factors.

\section{Theoretical Framework}

According to the review of theoretical principles, there are quite diverse empowerment theories, models and approaches each which can support the questions and objectives of this study. However, the theoretical basis of this study on the status of empowerment is specifically based on Melhem and Robbins's theory: According to conducted research by Yahya Melhem (2004), four factors have direct effective effects on the employee empowerment and they should be taken 
into account in competitive environment, so that the organizations can respond to rapid and high quality changes and then both employees and customers will become satisfied. Based on this model, the factors affecting the employees' empowerment are as follows: 1- Employees' knowledge and skills, 2- trust, 3- communication, and 4- motivation. Furthermore, based on the conducted studies by Robbins et al, it is important to provide a coherent integrated framework to clarify the roles of subjective, environmental, cognitive and behavioral variables in is empowerment process in which the relationship between organizational structure and workplace elements (structure of human resources and management practices) is effective (Robbins, 2002). In this model, the employee perceptions, opportunity to influence the work outcome, supportive nature of organization, and trust and commitment affect the workplace and organizational structure. The most important step in the process of employee empowerment is to provide the environment which creates an opportunity for personal exercise with a degree of authority and intrinsic motivation power in employees. Robbins et al believe that the personal differences, organizational structure, offices, workplaces, appraisal, rewarding, commitment and trust are the most important factors affecting the employee empowerment.

The following cases are other theoretical principles which have been used in this regard:

- Experimental studies by Spreitizer (1992) and Mishra (1992) who have argued that five factors namely 1) sense of self-efficacy, 2) sense of self-organization, 3) Personal acceptance of result, 4) sense of meaningfulness, and 5) sense of trust in others affect the successful empowerment.

- Counter (1983), Bandura (1986), and Hackman \& Oldham (1980) et al have considered nine certain ways for developing the empowerment as follows: 1) identifying clear vision and goals, 2) developing the personal mastery experiences, 3) modeling, 4) providing support, 5) emotional motivation, 6) providing the necessary information, 7) providing the necessary resources, 8) Linking with results, and 9) creating the self-confidence.

- Cameroon \& Cobain (1998) and Martin et al (1983), in turn, have provided the useful views on the human resource empowerment.

\section{Research Background}

Asgari (2007) has found that the employees' self-determination and levels of knowledge and skills, and the levels of communication and information flow have positive correlation with staff empowerment perception. Vakili (2004) has concluded that the behavioral, structural and managerial factors affect the staff empowerment. Padyar (2004) has also concluded that the establishment of cooperation spirit and participation in employees, creation of a continuous training system for human resources, establishment of an information technology system and human resources access to information, establishment of a meritocracy system in appointment and selection of human resources play the effective roles in employee empowerment.

Jafari et al (2008) have argued that the freedom of action and promotion of empowerment strategies are the effective solutions on empowering the academic experts.

Mehdizadeh and Khatami (2007) have conducted a research with the aim at evaluating the factors affecting the employee empowerment process in manufacturing-industrial organizations and found that the delegation of authority, the clear goals and modeling play the maximum roles respectively in determining the managerial strategies, organizational conditions and self- efficacy resources. The maximum impact on the employee empowerment belongs to managerial strategies and then the organizational conditions and self-efficacy resources.

Moshref et al (2007) have found that the level of employee empowerment is not satisfactory in terms of competence, effectiveness, significance, self-determination, and trust dimensions. The clear goals, performance appraisal system, rewarding system, employee training, and access to resources have positive correlation with empowerment, but the organizational structure has a negative correlation with it.

Ali Molla-Hosseini and Ehsan Arsalan (2009) have investigated the correlation between employee empowerment and organizational effectiveness in governmental offices and organizations of Rafsanjan city.

Saeid Abbasi and Bagherkord (2009) have identifies and explained the employee empowerment model in governmental organizations of Iran (Case Study: Yazd province).

The research on the studies abroad has produced the following results:

In a doctoral dissertation entitled "The study on the correlation between the employee empowerment and organizational justice", Pons Chradle (2004) as concluded that the staff empowerment affects the development of organizational justice, increase in employee job satisfaction and commitment.

Ken Marl and Merediti (2004) have considered the division of power, shared responsibilities, increased energy, and democratic development as the effects of empowerment.

Dee and DeeYomer (2005) have found that the communications, independence, team building and organizational 
commitment are correlated with psychological empowerment.

In a doctoral dissertation, Hiss, Marie (2004) has considered six dimensions of teacher empowerment as follows: career growth, self-efficacy, self-determination, full decision making situation, and effect.

In a research entitled "The criteria of organizational empowerment", Davis \& Steven (2002) have concluded that the employee motivation is one of the important and vital factors in competitive workplace of today's world. Furthermore, the empowerment of human resources is one of the newest ways of motivation in staff to improve the organizational performance and quality of organizations, and the criteria empowerment have been identified as follows: Goal setting and strategies by clear, explicit and changeable ways, employee participation at all aspects related to their profession, employee access to necessary information in organization, creating an atmosphere of mutual trust between managers and employees, and increasing the employee knowledge about their abilities.

Jennifer Edward (2002) has found that increasing the level of knowledge and skills in teachers and their participation in decision-making are among the most important strategies of empowerment.

Bill Lampers (2004) has provided the following empowerment strategies at schools according to his studies: Participation in information, participation in decision making, collective decision-making experience, creating a common vision, creating common beliefs, providing staff professional development, development of empowerment entities, and understanding the students' needs.

\section{Research Methodology}

This research is applied in terms of objective and has the descriptive type in terms of data collection. The literature of human resources empowerment is first studied and collected by providing the research plan, and then a questionnaire is designed for statistical population by designing the proposed conceptual model, and finally the conclusion is made after distributing and collecting the questionnaires and managers and experts' comments based on analysis of obtained data.

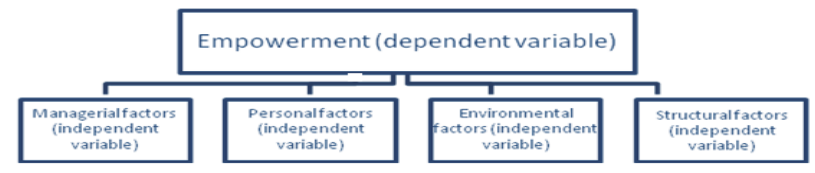

Conceptual Model (Framework) of Research (Primary and General)

\section{Brief introduction of Markazi Province}

\subsection{Geographical coordinates}

Markazi Province with the central city of Arak is located in central Iran between the circuits of $33^{\circ} 30^{\prime}$ to $35^{\circ}$ and $35^{\prime}$ North, and $48^{\circ} 57^{\prime}$ to $51^{\circ}$ East from Greenwich meridian.

This province is limited to Tehran and Qazvin provinces from the north, Hamedan province from the west, Lorestan and Isfahan provinces from the south, and Tehran, Isfahan, and Qom from the east.

There are various types of weather in different regions of Markazi Province including the semi-desert, temperate and cold mountainous climate. With an area of 29128 square kilometers, this province has allocated about 1.7 percent of the total area of Iran, and $33.9 \%$ of its area has mountains, $14.9 \%$ hills, $13.8 \%$ plateaus, and the rest of them have plains in terms of topographical features.

\subsection{Administrative-political and demographic divisions}

According to the latest country divisions in 2011, Markazi Province has 12 counties, 23 districts, 32 cities, 68 villages, 1273 settlements with residents, and 1814 settlements without residents, and it has a population of 1413959 inhabitants based on the General Population and Housing Census in 2011. From this population, 73.9 percent lived in urban areas and $1.26 \%$ in rural areas. In the same year, 715527 out of total population were male and 698432 female and the provincial population included 426937 households. 


\subsection{Cultural coordinates}

According to the archaeological and historical studies, the history of residence in this area of Iran dates from Second and Third Millennium BC.

Later, the civilizations were created in this land and their residuals are still existed in ancient hills in different parts of this land and this indicates the footprint of various ethnic groups who were integrated by arrival of Aryans and their integration.

The other ethnic groups including the Turks and Mongols settled in this land after Islam. Most of the people speak in Persian in Markazi Province. Turkish is also common in most of the villages around Arak, Sarband, Komijan and Saveh.

People speak in Raji language which roots in Medes' language and words.

Before the Arab invasion to Iran, the people followed Zoroastrianism in this land. The existence of numerous temples throughout the province is a proof of this claim. Most of the people are Muslims in this province (about 99.6). Armenians and Zoroastrians are the most important religious minorities who sporadically lived in these areas before Islam. Now, a few Jewish people also live in this province.

\subsection{Gross Domestic Product (GDP)}

According to the latest official statistics, the Gross Domestic Product (GDP) of Markazi province in 2012 was equivalent to 87948.8 billion Rials according to the current process of 2010 and this figure represents a $1.8 \%$ share of GDP in the whole country. In this respect, Markazi province is put in the rank 13 among other provinces of country.

\subsection{Review of business and production situation in Markazi province}

Markazi Province has a unique geographical location and is located in the linking route of North to South and West to East. It has very good economic capacities due to the energy pipelines (oil, gas and electricity), the establishment of industrial and academic centers, prominent religious and scientific figures, suitable agricultural lands and pastures, mineral reserves, proximity to industrial poles and consumer markets which all promote the empowerment in the agricultural, industry and service sectors.

Relative distribution of employment in major economic sectors of Markazi Province in 2013

\begin{tabular}{|c|c|c|}
\hline \multicolumn{2}{|c|}{ Title } & Percentage \\
\hline \multirow{2}{*}{ Workers in agricultural sector } & Province & 19.8 \\
\cline { 2 - 3 } & Country & 18.7 \\
\hline \multirow{2}{*}{ Workers in industrial sector } & Province & 38.2 \\
\cline { 2 - 3 } & Country & 33.6 \\
\hline \multirow{2}{*}{ Workers in service and trading sector } & Province & 41.7 \\
\cline { 2 - 3 } & Country & 47.6 \\
\hline
\end{tabular}

Source: Statistical Center of Iran

\subsubsection{Mining sector}

Markazi province has high mineral potential in the field of metallic and non metallic minerals. The development of utilized mines has been growing in recent years. 56 new operation licenses with a total investment of 241435 billion Rials were issued by Industries, Business and Mine Organization of Markazi province only in 2012 in order to utilize the mines of province. (Economics analysis report of Markazi Province, 2013: 225)

\subsubsection{Agricultural sector}

Markazi Province has diversity and high productivity in production of raw and processed agricultural items. Approximately 19 percent of provincial area consists of agricultural lands, $57 \%$ pasture lands, and 24 percent non-arable lands such as lakes, deserts, roads and cities. The total land area under cultivation was equivalent to 397.5 hectares in 2012 . However, the volume of local production of agricultural commodities was reduced due to the drought in some years. The total 
amount of agricultural production including farming, horticulture, livestock and fisheries was over 1942.2 thousand tons in 2012. Furthermore, the total value of agricultural production in that year was over 31794 billion Rials. (Ibid: 231)

\subsubsection{Business sector}

In 2012, Markazi Province had over \$ 827 million of exports with the volume of 760 thousand tons which was $2.5 \%$ of total exports value in that year. The value of provincial imports was $\$ 202$ million in the mentioned period with the volume of 61.7 tons and equivalent to $0.3 \%$ of the total value of imports in the country. The main export items of province include the live aquarium fish, apartment flowers, types of glass and mirror, power transmission tower, empty cylinder, Aluminum ingot, ceramic, and tile, and the main import items include knitting machine, Cold-rolled iron sheet, polypropylene, cotton, car accessories, folding cranes, etc. Accordingly, the balance of trade was equivalent to $\$ 625.3$ million in 2012. (Ibid: 242)

\subsubsection{Industry sector}

Markazi Province has a considerable industrial advantage by taking second place in the field of strategic and mother industries as well as fourth place of industrial development among all provinces of country. Only in 2012, over 961 licenses of new construction were issued for building or developing the industrial units in Markazi Province. This value shows more than 12.7 percent of growth compared to 2011. The volume of investment on these construction licenses was over 46730 billion Rials in that period and the number of predicted jobs was totally 24237 people in them. 260 operation licenses were issued in Markazi Province in the same year. (Ibid: 219)

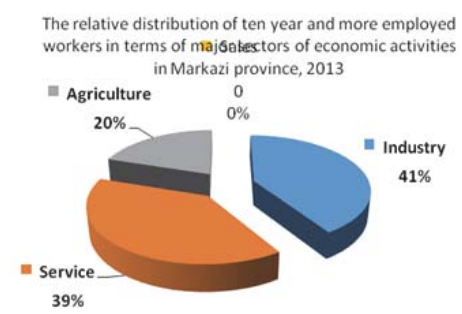

Source: Statistical Center of Iran

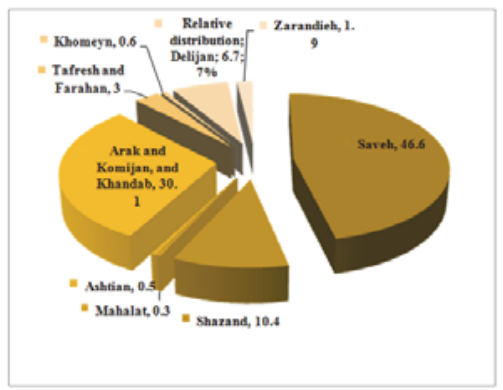

Relative Distribution of Workers in Industrial Workshops in Terms of Cities

Source: Statistical Center of Iran, 2013

Number of workshops with 50 workers in terms of cities, 2013

\begin{tabular}{|c|c|c|c|c|}
\hline \multirow{2}{*}{ City } & \multicolumn{4}{|c|}{ Total workshops } \\
\cline { 2 - 5 } & $\mathbf{1 0 - 4 9}$ people & $\mathbf{5 0 - 9 9}$ people & $\mathbf{1 0 0}$ and more & Sum \\
\hline Whole province & 0 & 138 & 120 & 257 \\
\hline Arak & 0 & 34 & 31 & 64 \\
\hline Tafresh & 0 & 3 & 4 & 7 \\
\hline Delijan & 0 & 15 & 10 & 25 \\
\hline
\end{tabular}




\begin{tabular}{|c|c|c|c|c|}
\hline Zarandieh & 0 & 3 & 4 & 7 \\
\hline Saveh & 0 & 80 & 63 & 143 \\
\hline Shazand & 0 & 1 & 5 & 6 \\
\hline Other cities & 0 & 2 & 3 & 5 \\
\hline
\end{tabular}

Source: Statistical Center of Iran

\section{Research Domain}

A- Thematic domain: The thematic domain means to investigate the variables affecting the employee empowerment.

B- Time domain: This study is conducted in 2014 and its data belong to the second half of 2014.

C- Spatial domain: Spatial domain refers to Markazi Province industries including the industries located in Arak, Khomeyn, Mahallat, Khandab, Shazand, Ashtian, Tafresh and Saveh cities.

\section{Research Objectives}

Main objective: The main objective of this research is to investigate the variables affecting the human resources empowerment in Markazi Province.

\section{Hypotheses}

Various hypotheses have been developed for conducting this research, but we have obtained four main hypotheses according to the studies and consideration of theoretical framework; and each of them have numerous sub-factors.

These four hypotheses are as follows:

1- There is a significant correlation between the structural factors and employee empowerment.

2- There is a significant correlation between the environmental factors and employee empowerment.

3- There is a significant correlation between the personal factors and employee empowerment.

4- There is a significant correlation between the managerial factors and employee empowerment.

Brief analysis of questionnaire items:

- The target questionnaire, which collected the required data, consists of several parts. The preliminary part seeks for information about the total state of organization (company) and finally a question is raised about the knowledge of existing empowerment models.

Section 1 contains 21 questions from which 9 first questions are about the respondent's view about the empowerment, and questions 10 to 21 are about the factors affecting the empowerment in the organization (most of the personal factors).

The second part, which is presented after question 21 and goes on to 44 questions, is about the factors affecting the empowerment as a whole (environmental, managerial, structural and personal).

The third section asks the respondent to write his personal opinion about priorities, and the priority of employee empowerment factors.

The questions 10 to 44 are utilized in statistical analysis of questionnaire and these questions analyze the personal, environmental, managerial and structural factors.

- Pearson correlation coefficient is applied in statistical analysis of correlation between the independent and dependent variables (factors).

- A total of 200 questionnaires are distributed among target population in 43 companies of Markazi Province and finally 189 questionnaires are collected from 40 companies and then analyzed.

\section{Validity}

The validity is a tool for measurement of target feature in any research. We need to be aware of validity to trust in precision of measurement data. The face validity is utilized to determine the validity of questionnaire (referring to Judges) in this research. In other words, we have utilized the experts, judges and scholars' views in order to build the questionnaire items and validate it. 


\section{Reliability}

The internal consistency of items and questions and Cronbach's alpha coefficient, which is based on it, are among the most common methods of investigating the reliability of measurement tools. The reliability of measurement tools in social studies is among the most important obvious cognitive subjects because it will be impossible to trust in results of empirical studies without it. Therefore, we have utilized Cronbach's alpha test in order to know whether the measurement tools will have the same results as well as evaluating the reliability of variables. It is first implemented on 33 questionnaires of statistical population, and then its reliability is measured through SPSS software. The coefficient is obtained equal to $90 \%$ based on the target formula, and thus it can be concluded that the questionnaire has high reliability.

$$
\propto=\frac{K}{\mathrm{~K}-1}\left(1-\frac{\sum_{i}^{k}=1 S_{i}^{2}}{S^{2}}\right.
$$

Where, $\mathrm{K}$ is number of questions, $S_{\mathrm{i}}^{2}$ is the variance of each question and $\mathrm{S}^{2}$ is the variance of total questions.

The correlation coefficient is a mathematical index which describes the direction and amount of correlation between two variables. The correlation coefficient is used for distribution of two or more variables. If the values of two variables are changed similarly, it means that the variable will be decreased or increased by decreasing or increasing the other variable, so that their correlation can be shown in an equation, and thus there is a correlation between these two variables. formula.

Our mathematical analysis is based on the Pearson correlation coefficient and thus we have used the following

$$
P x, y=\frac{\operatorname{cov}(x, y)}{\sqrt{(\operatorname{var} x)(\text { var } y)}}=\frac{\sigma x y}{\sigma x \sigma y}
$$

As already explained, the structural, personal, environmental and managerial variables are our independent variables, and the empowerment is the dependent variable.

\begin{tabular}{|c|c|c|c|c|c|}
\hline & Structural & Environmental & Personal & Managerial & Empowerment \\
\hline Pearson structural coefficient & 1 & 0.465 & 0.400 & 0.410 & 0.729 \\
\hline Sig & & 0.00 & 0.00 & 0.00 & 0.00 \\
\hline Total & 189 & 189 & 189 & 189 & 189 \\
\hline Environmental coefficient & 0.465 & 1 & 0.202 & 0.088 & 0.524 \\
\hline Sig & 0.00 & & 0.005 & 0.227 & 0.00 \\
\hline Total & 189 & 189 & 189 & 189 & 189 \\
\hline Personal coefficient & 0.400 & 0.202 & 1 & 0.314 & 0.844 \\
\hline Sig & 0.00 & 0.005 & & 0.00 & 0.00 \\
\hline Total & 189 & 189 & 189 & 189 & 189 \\
\hline Managerial coefficient & 0.410 & 0.088 & 0.214 & 1 & 0.602 \\
\hline Sig & 0.00 & 0.227 & 0.00 & & 0.00 \\
\hline Total & 189 & 189 & 189 & 189 & 189 \\
\hline Empowerment coefficient & 0.729 & 0.524 & 0.844 & 0.602 & 1 \\
\hline Sig & 0.00 & 0.00 & 0.00 & 0.00 & \\
\hline Total & 189 & 189 & 189 & 189 & 189 \\
\hline
\end{tabular}

Table of correlation between variables through Pearson method

It is shown that according to Pearson correlation coefficient, the highest correlation belongs to personal, structural, environmental, managerial, and finally the empowerment factors respectively. Therefore, according to the study on the correlation between the empowerment and factors influencing it is industries of Markazi Province, the personal factors (844\%), structural (729\%) managerial (602\%), and environmental (524\%) have the highest correlation and effectiveness. Accordingly, we can refer to the following model. 


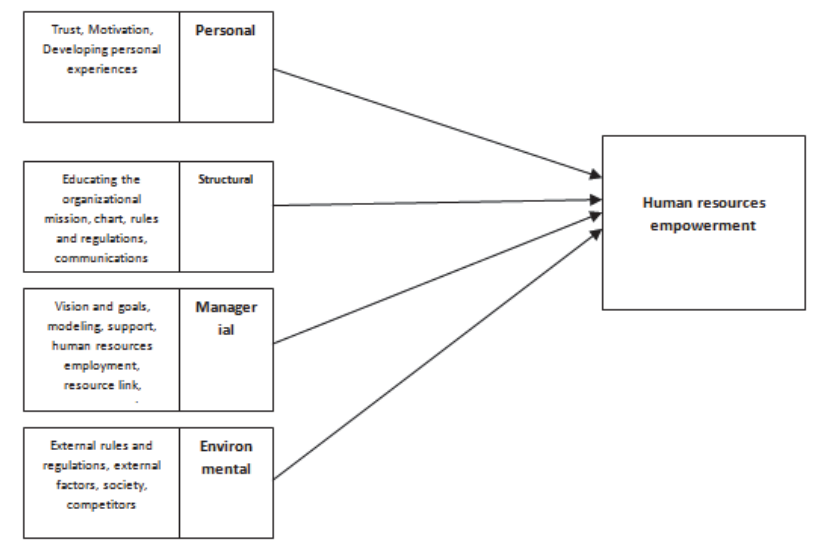

Human resource empowerment model in industries of Markazi Province

\section{Conclusion}

The human resource is the most important and vital asset of any organization. The quality and capabilities of human resources are the most important factor of organizational survival. The capable human resources create a powerful organization which is an environment where the employees work together in different groups. The employee empowerment is the managers' key attempts in innovation, decentralization and removal of bureaucracy in organizations. Due to the individual empowerment, the managers and organization achieve their goals faster and without wasting the resources. The employees consider the organization and jobs as their own assets and thus they are proud of their work in that organization due to the empowerment. Without empowerment, neither the managers nor organizations can be successful in the long term.

As mentioned above, the aim of this study is to investigate the variables which affect the human resource empowerment in industries of Markazi Province. Four hypotheses are presented in this regard and they are eventually proven by Pearson correlation coefficient. The maximum correlation is obtained empowerment and personal factor, and then the structural, managerial and environmental factors in human resources.

Finally, we have provided the relevant model. Therefore, we should pay more attention to personal, structural, managerial and environmental factors respectively in order to empower the human resources in industries of Markazi Province.

\section{References}

Robbins, P., Principles of organizational behavior, Translated by Parsaeian and Arabi, Tehran, Cultural Research Bureau, 2008.

Blanchard, Kenneth; Hersey, Paul; Organizational behavior management, translated by Allagheband, Tehran, Amirkabir, 2001.

Abdollahi, Bijan; Naveh-Ebrahim, Abdolrahim; Employee empowerment: A gold key of human resource management, Tehran, Virayesh, 2006.

Amirkhani, Amir-Hossein, Psychological empowerment of human resources: Views and dimensions, Proceedings of the Third Conference on human resources, Tehran, 2006.

Norouzzadeh, Rerza; Aghdasi, Samaneh; Factors affecting the human resource empowerment, Bi-Quarterly Journal of human resource management research, Tehran, 2013.

Feizi, Tahereh; Zolfaghari-Moghaddam, Asieh; Identification of variables associated with psychological empowerment in employees at education organization of Qom City, management culture, Qom, 2008.

Kord, Bagher; The study on the factors associated with employee empowerment in small and medium enterprises, General Management Research, Tehran, 2012.

Statistical Center of Iran, Statistical Yearbook of Markazi Province, 2013.

Economic analysis report of Markazi Province, Department of Economic and Financial Affairs, 2013.

Blanchard. K H \& Carlor, J.P. and Randolph. A. (2002) Empowerment Take More Than one Minute .Barrett-Kohler. Sanfrancisco

Robbins, T.L, Crinom. D., Fredendal L.D (2002), An Integrative model of the Empowerment process .Human Resource Management Review.vol .12

Spreitizer, G.M. (1997). When organization dares: the dynamics of individual empowerment in the work place .Ph.D. dissertation, University of Michigan 